\title{
Novel CAD-ALK gene rearrangement is drugable by entrectinib in colorectal cancer
}

\author{
Alessio Amatu ${ }^{1}$, Alessio Somaschini ${ }^{2}$, Giulio Cerea ${ }^{1}$, Roberta Bosotti ${ }^{2}$, Emanuele Valtorta ${ }^{1}$, \\ Pasquale Buonandi ${ }^{1}$, Giovanna Marrapese ${ }^{1}$, Silvio Veronese ${ }^{1}$, David Luo ${ }^{3}$, Zachary Hornby ${ }^{3}$, Pratik Multani ${ }^{3}$, \\ Danielle Murphy ${ }^{3}$, Robert Shoemaker ${ }^{3}$, Calogero Lauricella ${ }^{1}$, Laura Giannetta ${ }^{1}$, Martina Maiolani ${ }^{1}$, \\ Angelo Vanzulli ${ }^{1}$, Elena Ardini ${ }^{2}$, Arturo Galvani ${ }^{2}$, Antonella Isacchi ${ }^{2}$, Andrea Sartore-Bianchi ${ }^{1,5}$ \\ and Salvatore Siena ${ }^{\star}, 1,4,5$
}

${ }^{1}$ Niguarda Cancer Center, Ospedale Niguarda Ca' Granda, 20162 Milan, Italy; ${ }^{2}$ Business Unit Oncology, Nerviano Medical Sciences Srl, Viale Pasteur 10, 20014 Nerviano, MI, Italy; ${ }^{3}$ Ignyta, Inc., 11111 Flintkote Avenue, San Diego, CA 92121, USA and ${ }^{4}$ Università degli Studi di Milano, 20122 Milan, Italy

Background: Activated anaplastic lymphoma kinase (ALK) gene fusions are recurrent events in a small fraction of colorectal cancers (CRCs), although these events have not yet been exploited as in other malignancies.

Methods: We detected ALK protein expression by immunohistochemistry and gene rearrangements by fluorescence in situ hybridisation in the ALKA-372-001 phase I study of the pan-Trk, ROS1, and ALK inhibitor entrectinib. One out of 487 CRCs showed ALK positivity with a peculiar pattern that prompted further characterisation by targeted sequencing using anchored multiplex PCR.

Results: A novel ALK fusion with the carbamoyl-phosphate synthetase 2, aspartate transcarbamylase, and dihydroorotase (CAD) gene (CAD-ALK fusion gene) was identified. It resulted from inversion within chromosome 2 and the fusion of exons 1-35 of CAD with exons 20-29 of ALK. After failure of previous standard therapies, treatment of this patient with the ALK inhibitor entrectinib resulted in a durable objective tumour response.

Conclusions: We describe the novel CAD-ALK rearrangement as an oncogene and provide the first evidence of its drugability as a new molecular target in CRC.

Activated anaplastic lymphoma kinase $(A L K)$ gene fusions, found in haematological and solid malignancies, have been successfully exploited as therapeutic targets in lung and inflammatory myofibroblastic tumours using the ALK kinase inhibitors crizotinib and ceritinib (Grande et al, 2011; Awad and Shaw, 2014). In colorectal cancer (CRC), ALK rearrangements are recurrent events found in $0.4-3 \%$ of samples analysed and involve as partner genes EML4, C2orf44, or PRKAR1A (reviewed by Aisner et al (2014)). Although expression of the resulting chimaeric transcripts was shown in some patients by PCR with reverse transcription (RTPCR) analysis, the final evidence of ALK fusion protein expression in these tumours has been lacking, hampering the exploitation of these observations in the therapeutic setting of CRC.

Entrectinib is a selective pan-TRK, ROS1, and ALK kinase inhibitor with strong preclinical activity in multiple cancer models where these targets are constitutively activated (Ardini et al, 2013; De Braud et al, 2014; Sartore-Bianchi et al, 2015). Entrectinib is currently being developed in phases I-II clinical studies in patients with tumours harbouring NTRK, ROS1, or ALK gene aberrations (De Braud et al, 2014).

Screening of 487 CRC formalin-fixed, paraffin-embedded (FFPE) samples for ALK expression by immunohistochemistry

\footnotetext{
*Correspondence: Professor S Siena; E-mail: salvatore.siena@ospedaleniguarda.it

${ }^{5}$ These authors contributed equally as senior authors.
}

Received 17 July 2015; revised 12 October 2015; accepted 15 October 2015; published online 3 December 2015 
(IHC) within the ALKA-372-001 phase I, first-in-human study of entrectinib identified a sample with high levels of ALK protein expression. This finding was extremely atypical and highly suggestive of a rearrangement event placing the $A L K$ gene, not normally expressed in the colon, under ectopic control of a fusion partner promoter. We then confirmed by fluorescence in situ hybridisation (FISH) that an ALK gene rearrangement was in fact present (Medico et al, 2015). Here we report the molecular and clinical study of this CRC patient, which led to the discovery of a novel $A L K$ rearrangement that was present in the primary tumour, in a thoracic lymph node, and in liver metastases. We also describe the objective response of this patient to entrectinib treatment, providing the first evidence of an $A L K$ gene rearrangement as a clinically relevant therapeutic target in CRC.

\section{MATERIALS AND METHODS}

We detected ALK protein expression by IHC using the ALK mouse monoclonal antibody 5A4 (N-Histofine ALK Detection Kit; Nichirei Biosciences Inc., Histo-Line Laboratories s.r.l, Milan, Italy) and gene rearrangements by FISH using the LSI ALK Break Apart FISH Probe Kit (Vysis, Abbott Molecular, Abbott Park, IL, USA) as previously described (Medico et al, 2015).

To identify the $A L K$ rearrangement partner, we subjected RNA from the primary tumour FFPE clinical samples to next-generation sequencing (NGS) analysis using targeted sequencing technology based on anchored multiplex PCR (Archer AMP; ARCHERDX, Boulder, CO, USA), customised for the detection of rearrangements of selected tyrosine kinases, including ALK, and allowing simultaneous identification of the fusion partner through an unbiased approach that did not require a priori knowledge of the gene fusion event. PCR/Sanger sequencing of the chimaeric transcript using primers spanning the fusion junction region confirmed the rearrangement. Mutations in KRAS and NRAS exons 2, 3, and 4 and BRAF exon 15; HER2 amplification; and ROS1 and NTRK rearrangements were assessed as previously described (Sartore-Bianchi et al, 2015; Siravegna et al, 2015; Valtorta et al, 2015).

The patient was enrolled in the ALKA-372-001 phase I study (EudraCT Number: 2012-000148-88) and received treatment with entrectinib $400 \mathrm{mg} \mathrm{m}^{-2}$ po $\mathrm{qd}$, which was recently determined to be the recommended phase II dose (RP2D). Objective tumour response was measured by computed tomography (CT) using the Response Evaluation Criteria in Solid Tumours (RECIST version 1.1) (Eisenhauer et al, 2009).

\section{RESULTS}

The patient was a 53-year-old woman with metastatic CRC (brain, thoracic lymph nodes and liver) who was in disease progression after standard therapies, including surgery (right hemicolectomy), external beam radiation therapy to the CNS and thoracic lymph nodes, and two lines of chemotherapy, both based on oxaliplatin, 5-fluorouracil/leucovorin, and bevacizumab, administered before and after the radiation therapy. The primary tumour resected in March 2012 was a grade 3 adenocarcinoma of the right colon metastatic to the supraclavicular lymph node biopsied in April 2012. At progression in March 2015, the patient gave written informed consent to a biopsy of liver metastases. All samples showed histology of primary CRC and CRC metastases (Figure $1 \mathrm{~A}-\mathrm{C} 1$ ). High levels of ALK protein were observed by IHC in the primary tumour, thoracic lymph node and liver
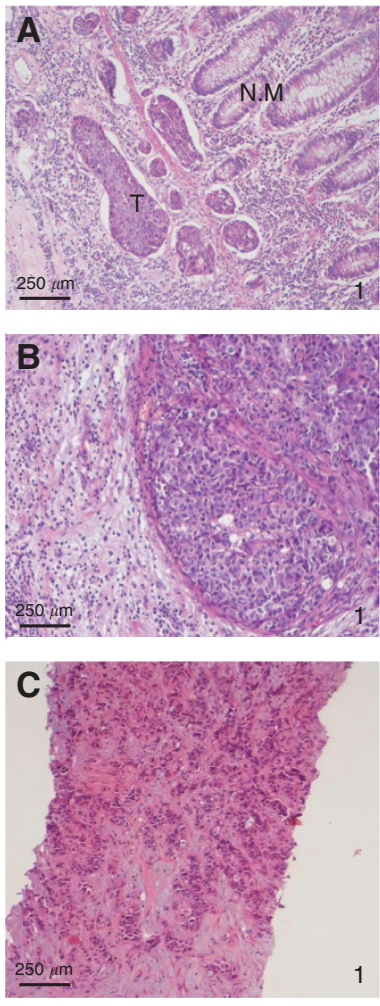
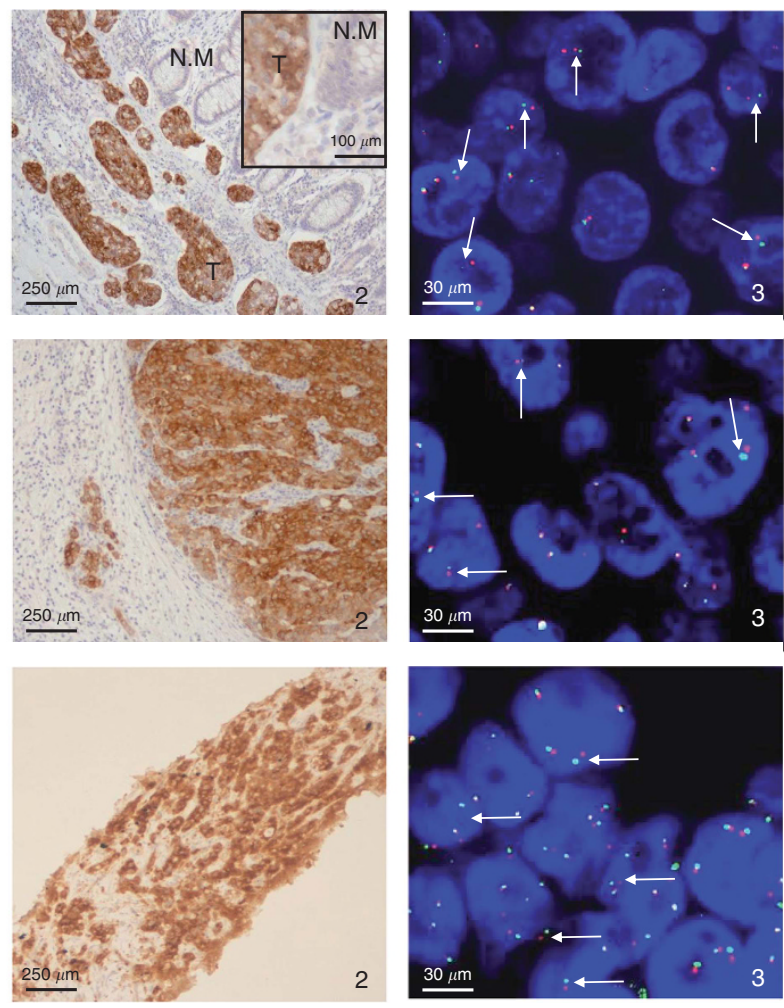

Figure 1. Histological, immunohistochemical, and fluorescence in situ hybridisation analyses of the primary right colonic tumour, lymph node, and liver metastasis of the case presented. Haematoxylin \& eosin, immunohistochemical and FISH images of the primary colon tumour (A 1-3; N.M: normal mucosa, T: tumour), lymph node (B 1-3), and liver metastasis (C 1-3) of the patient presented in this report, showing malignant tumour (A1, B1, C1), ALK protein overexpression (A2, B2, C2) and ALK gene rearrangements (A3, B3, C3, white arrows). Original magnification of images: $\times 100$ for haematoxylin \& eosin and immunohistochemical staining, Insert $\times 400 ; \times 630$ for FISH analysis. 
A

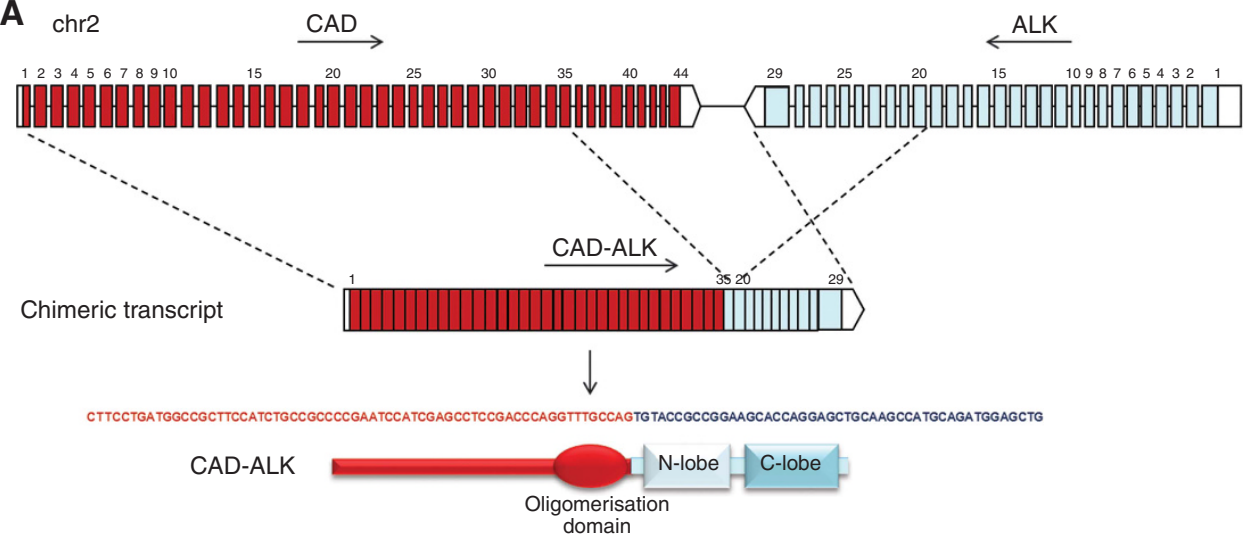

B

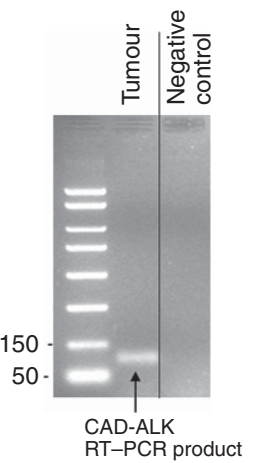

Figure 2. Identification of the CAD-ALK gene rearrangement. (A) The upper section shows a schematic representation of the CAD-ALK genomic DNA rearrangement and the resulting transcript. The sequence spanning the rearrangement junction is also shown. Exons are represented by coloured boxes, and introns are represented by lines: CAD in red and ALK in light blue. The lower section shows the functional domains conserved in the chimaeric CAD-ALK protein. (B) Characterisation of the CAD-ALK transcript by PCR. Agarose gel showing amplification with primers for the rearranged CAD-ALK chimaeric transcript, spanning CAD exon 35 to $A L K$ exon 20. The tumour sample was compared with a negative control sample (U138-MG cell line, expressing ALK full length).

metastasis (Figure $1 \mathrm{~A}-\mathrm{C} 2$ ), and the underlying $A L K$ abnormality consisted of an $A L K$ rearrangement as demonstrated by FISH (Figure 1A-C3). Further molecular characterisation showed wild-type KRAS and NRAS exons 2, 3, and 4 and BRAF exon 15, no amplification of HER2, and no ROS1 or NTRK rearrangements. Moreover, we found no amplification of the $A L K$ gene. Further investigation by NGS identified an $A L K$ rearrangement resulting from an inversion within chromosome 2, fusing exons 1-35 of the carbamoyl-phosphate synthetase 2, aspartate transcarbamylase, and dihydroorotase $(C A D)$ gene with exons 20-29 of $A L K$ (C35-A20), and confirmed by PCR/Sanger sequencing (Figure $2 \mathrm{~A}$ and $\mathrm{B}$ ).

These findings prompted us to enrol the patient in the ALKA-372-001 phase I study at the RP2D of $400 \mathrm{mg} \mathrm{m}^{-2}$ po qd of entrectinib, starting in March 2015. The patient presented at baseline with ECOG performance status 0, stable and asymptomatic CNS disease, and progressive liver metastases. The first-response assessment via CT, which was performed in April 2015, 4 weeks after the beginning of treatment, showed a partial response per RECIST v1.1 with a decrease in the sum of the target lesions by $38 \%$ (Figure 3). Computed tomography performed 4 weeks later in May 2015 confirmed this response. CNS metastases (brain and cerebellum) were stable. No drug-related adverse events were recorded, and the patient was responding and still under treatment with entrectinib as of July 2015.

\section{DISCUSSION}

In CRC, recurrent genetic lesions conferring oncogene addiction are only recently emerging as experimental therapeutic targets. These lesions are presently confined to gene amplifications and mutations, such as HER2 (Siena et al, 2015b), MET (Bardelli et al, 2013), and BRAF (Yaeger et al, 2015). Activating gene rearrangements representing new potential therapeutic opportunities have only recently started to be exploited in the clinic (Ardini et al, 2014). We recently reported the existence of NTRK1 rearrangements as recurrent events in CRC, and we discovered TRKA as a target in CRC by identifying an LMNA-NTRK1 rearrangement, leading to sensitivity to treatment with entrectinib in a patient with CRC refractory to standard therapies (Ardini et al, 2014; Sartore-Bianchi et al, 2015). ALK rearrangements have also been reported in CRC (Aisner et al, 2014), but no data are available
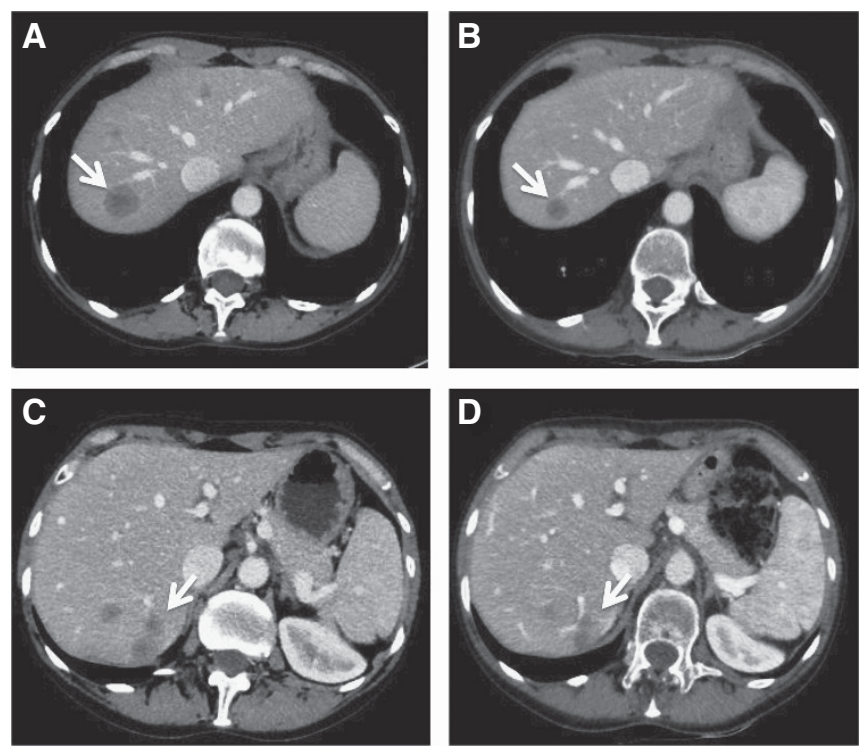

Figure 3. Computed tomography (CT) scans showing the objective tumour response to entrectinib. The baseline abdominal CT scan of March 2015 demonstrated liver involvement with the two largest lesions both in hepatic segment VII, measuring 27 and $33 \mathrm{~mm}$ in longest diameter, respectively ( $\mathbf{A}, \mathbf{C}$ arrows). At the first-response assessment, in April 2015, 4 weeks after the initiation of treatment, CT showed a RECIST partial response with an overall decrease in the sum of the target lesions of $38 \%$, and lesions in segment VII displaying longest diameters of 15 and $22 \mathrm{~mm}$ (B, D arrows).

regarding the effectiveness of specific ALK therapeutic inhibition in this clinical setting.

We recently applied IHC as a screening strategy to detect $A L K$ rearrangements in CRC, leading to the identification of a positive sample harbouring an $A L K$ rearrangement, as confirmed by FISH (Medico et al, 2015). Here we report the molecular characterisation of this metastatic CRC, revealing a novel CAD-ALK gene rearrangement, and the successful treatment of this patient with entrectinib.

The $C A D$ gene encodes a trifunctional protein that is associated with the enzymatic activities of the first three enzymes in the 
six-step pathway of pyrimidine biosynthesis: carbamoylphosphate synthetase (CPS II), aspartate transcarbamoylase, and dihydroorotase (Grande-García et al, 2013). CAD is expressed in normal colonic tissue, and its expression is increased in inflammatory bowel disease (Richmond et al, 2012). CAD is also detected at medium-high levels in CRC by IHC (Uhlén et al, 2015). The $C A D-A L K$ chimaeric gene encompassed CAD exons 1-35 fused to the canonical exon 20 recombination site that was previously reported for $A L K$ gene fusions (Grande et al, 2011; Awad and Shaw, 2014). The chimaeric protein comprises the carbamoyl phosphate synthetase large-chain oligomerisation domain fused to the entire ALK kinase domain, potentially resulting in constitutive dimerisation causing ALK kinase activation. The chimaeric protein is expected to be sensitive to ATP competitive inhibitors such as entrectinib because it encompasses a drug-binding region identical to the corresponding wild-type ALK kinase. A recent IHC screening effort to detect ALK expression in 172 Korean CRC cases resulted in the identification of a strongly positive rectal adenocarcinoma sample, which was found to harbour a $C A D-A L K$ (C35-A20) rearrangement (Lee et al, 2015). In addition, one of the 50 CRC patients enrolled in a pathway-directed therapeutic trial (NEXT-1) was also found to harbour an EML4-ALK (E21, A20) rearrangement (Lee et al, 2015). These data confirm the existence of $A L K$ rearrangements as rare recurrent events in CRC.

Therapeutic inhibition of EML4-ALK with entrectinib in patients with non-small cell lung cancer has resulted in remarkable objective responses and clinical benefit (Siena et al, 2015a). We provide the first evidence that treatment with an ALK inhibitor is effective in metastatic CRC involving an $A L K$ gene rearrangement. Entrectinib at RP2D rapidly induced tumour shrinkage, achieving an objective response within 4 weeks of commencing treatment, which lasted $>4$ months and was maintained at the time of the present report (July 2015). Although activated ALK rearrangements are rare events in CRC (Aisner et al, 2014; Medico et al, 2015), a screening strategy based on simple ALK assessment by IHC followed by targeted NGS based on anchored multiplex PCR (Zheng et al, 2014) represents a feasible strategy, which will enhance the identification of patients who can benefit from entrectinib treatment in CRC and other histologies (Siena et al, $2015 b)$. The reason for reporting on a single case is the rarity of gene fusions in CRC; a large series for clinical studies would be possible only if pharmaceutical interest and rationale are triggered by the knowledge of successful uncommon cases such as this and other recently reported translocations (Sartore-Bianchi et al, 2015).

The innovation of the present report resides in the discovery of the novel $C A D-A L K$ rearranged gene in CRC, whose pharmaceutical blockade with a single agent, entrectinib, led to a clinically meaningful anti-tumour effect. Thus for the first time, we provide the proof of concept that $A L K$ alterations can act as drivers in CRC, building a new step towards personalised therapy in this clinical setting.

\section{ACKNOWLEDGEMENTS}

We thank Dr Antonio Maestri for patient referral, Dr Mauro Truini for supervising histology diagnosis and Dr Laura Raddrizzani for molecular analyses. This work was supported by grants from Fondazione Oncologia Niguarda Onlus, grant Terapia Molecolare dei Tumori (AS-B, SS); Associazione Italiana Ricerca Cancro (AIRC), grant 2010-2015 Special Program Molecular Clinical Oncology $5 \times 1000$ project 9970 (SS); European Union 7th Framework Programme, grant 259015 COLTHERES (SS); and Community Research and Development Information Service (CORDIS), grant 635342 MoTriColor (Molecularly guided trials with specific treatment strategies in patients with advanced newly molecular defined subtypes of colorectal cancer) (SS).

\section{CONFLICT OF INTEREST}

ASB is a consultant/advisory member for Amgen, Bayer, and Merck-Serono. SS is a consultant/advisory member for Amgen, Bayer, Eli-Lilly, Merck-Serono, Merus, Novartis, Roche, Sanofi, and Ignyta. DL, ZH, PM, DM, and RS are employees of Ignyta. AS, RB, EA, AG and AI are employees of Nerviano Medical Sciences. The remaining authors declare no conflict of interest.

\section{REFERENCES}

Aisner DL, Nguyen TT, Paskulin DD, Le AT, Haney J, Schulte N, Chionh F, Hardingham J, Mariadason J, Tebbutt N, Doebele RC, Weickhardt AJ, Varella-Garcia M (2014) ROS1 and ALK fusions in colorectal cancer, with evidence of intratumoral heterogeneity for molecular drivers. Mol Cancer Res 12: 111-118.

Ardini E, Bosotti R, Borgia AL, De Ponti C, Somaschini A, Cammarota R, Amboldi N, Raddrizzani L, Milani A, Magnaghi P, Ballinari D, Casero D, Gasparri F, Banfi P, Avanzi N, Saccardo MB, Alzani R, Bandiera T, Felder E, Donati D, Pesenti E, Sartore-Bianchi A, Gambacorta M, Pierotti MA, Siena S, Veronese S, Galvani A, Isacchi A (2014) The TPM3-NTRK1 rearrangement is a recurring event in colorectal carcinoma and is associated with tumor sensitivity to TRKA kinase inhibition. Mol Oncol 8: 1495-1507.

Ardini E, Meninchicheri M, Banfi P, Casero D, Giorgini ML, Saccardo MB, Amboldi N, Avanzi N, Orsini P, Isacchi A, Presenti E, Galvani A (2013) The ALK inhibitor NMS-E628 also potently inhibits ROS1 and induces tumor regression in ROS-driven models. Proceedings of the 104th Annual Meeting of the American Association for Cancer Research; 6-10 April 2013; Washington, DC. Cancer Res 73(8 Suppl): Abstract no. 2092.

Awad MM, Shaw AT (2014) ALK inhibitors in non-small cell lung cancer: crizotinib and beyond. Clin Adv Hematol Oncol 12: 429-439.

Bardelli A, Corso S, Bertotti A, Hobor S, Valtorta E, Siravegna G, Sartore-Bianchi A, Scala E, Cassingena A, Zecchin D, Apicella M, Migliardi G, Galimi F, Lauricella C, Zanon C, Perera T, Veronese S, Corti G, Amatu A, Gambacorta M, Diaz LA, Sausen M, Velculescu VE, Comoglio P, Trusolino L, Di Nicolantonio F, Giordano S, Siena S (2013) Amplification of the MET receptor drives resistance to anti-EGFR therapies in colorectal cancer. Cancer Discov 3: 658-673.

De Braud F, Pilla L, Niger M, Damian S, Bardazza B, Martinetti A, Pelosi G, Marrapese G, Palmeri L, Cerea G, Valtorta E, Veronese S, Sartore-Bianchi A, Ardini E, Martignoni M, Isacchi A, Luo D, Freddo L, Siena S (2014) RXDX-101, an oral Pan-Trk, ROS1, and ALK inhibitor, in patients with advanced solid tumors with relevant molecular alterations. Ann Oncol 25: iv146-iv164.

Eisenhauer EA, Therasse P, Bogaerts J, Schwartz LH, Sargent D, Ford R, Dancey J, Arbuck S, Gwyther S, Mooney M, Rubinstein L, Shankar L, Dodd L, Kaplan R, Lacombe D, Verweij J (2009) New response evaluation criteria in solid tumours: revised RECIST guideline (version 1.1). Eur J Cancer 45: 228-247.

Grande E, Bolós M-VV, Arriola E (2011) Targeting oncogenic ALK: a promising strategy for cancer treatment. Mol Cancer Ther 10: 569-579.

Grande-García A, Lallous N, Díaz-Tejada C, Ramón-Maiques S (2013) Structure, functional characterization, and evolution of the dihydroorotase domain of human CAD. Structure 22: 185-198.

Lee J, Kim H, Hong J, Wang K, Kim S, Jang J, Kim S, Park J, Lim H, Kang W, Park Y, Lee J, Lee W, Park Y, Huh J, Yun S, Do I-G, Kim S, Balasubramanian S, Stephens P, Ross J, Li G, Hornby Z, Ali S, Miller V, Kim K-M, Ou S-H (2015) Detection of novel and potentially actionable anaplastic lymphoma kinase (ALK) rearrangement in colorectal adenocarcinoma by immunohistochemistry screening. Oncotarget 6(27): 24320-24332.

Medico E, Russo M, Picco G, Cancelliere C, Valtorta E, Corti G, Buscarino M, Isella C, Lamba S, Martinoglio B, Veronese S, Siena S, Sartore-Bianchi A, Beccuti M, Mottolese M, Linnebacher M, Cordero F, Di Nicolantonio F, Bardelli A (2015) The molecular landscape of colorectal cancer cell lines unveils clinically actionable kinase targets. Nat Commun 6: 7002. 
Richmond AL, Kabi A, Homer CR, Marina-García N, Nickerson KP, Nesvizhskii AI, Sreekumar A, Chinnaiyan AM, Nuñez G, McDonald C (2012) The nucleotide synthesis enzyme CAD inhibits NOD2 antibacterial function in human intestinal epithelial cells. Gastroenterology 142: 1483-92.e6.

Sartore-Bianchi A, Ardini E, Bosotti R, Amatu A, Valtorta E, Somaschini A (2015) A novel LMNA-NTRK1 gene fusion confers sensitivity to entrectinib in metastatic colorectal cancer. J Natl Cancer Inst 108(1).

Siena S, Drillon A, Ou S-H, Farago A, Patel M, Bauer T, Hong D, Liu S, Lee J, Patel R, Schechet L, Luo D, Chow Maneval E, Multani P, De Braud F (2015a) Entrectinib (RXDX-101), an oral pan-Trk, ROS1, and ALK inhibitor in patients with advanced solid tumors harboring gene rearrangements. Eur J Cancer 51(Suppl 3): S724-S725.

Siena S, Sartore-Bianchi A, Lonardi S, Trusolino L, Martino C, Bencardino K, Leone F, Zagonel V, Torri V, Siravegna G, Amatu A (2015b) Trastuzumab and lapatinib in HER2-amplified metastatic colorectal cancer patients (mCRC): The HERACLES trial. J Clin Oncol 33: 3508.

Siravegna G, Mussolin B, Buscarino M, Corti G, Cassingena A, Crisafulli G, Ponzetti A, Cremolini C, Amatu A, Lauricella C, Lamba S, Hobor S, Avallone A, Valtorta E, Rospo G, Medico E, Motta V, Antoniotti C, Tatangelo F, Bellosillo B, Veronese S, Budillon A, Montagut C, Racca P, Marsoni S, Falcone A, Corcoran RB, Di Nicolantonio F, Loupakis F, Siena S, Sartore-Bianchi A, Bardelli A (2015) Clonal evolution and resistance to EGFR blockade in the blood of colorectal cancer patients. Nat Med 21: 795-801.

Uhlén M, Fagerberg L, Hallström BMM, Lindskog C, Oksvold P, Mardinoglu A, Sivertsson A, Kampf C, Sjöstedt E, Asplund A, Olsson I, Edlund K, Lundberg E, Navani S, Szigyarto CA,
Odeberg J, Djureinovic D, Takanen JO, Hober S, Alm T, Edqvist P-HH, Berling H, Tegel H, Mulder J, Rockberg J, Nilsson P, Schwenk JM, Hamsten M, von Feilitzen K, Forsberg M, Persson L, Johansson F, Zwahlen M, von Heijne G, Nielsen J, Pontén F (2015) Proteomics. Tissue-based map of the human proteome. Science 347: 1260419.

Valtorta E, Martino C, Sartore-Bianchi A, Penaullt-Llorca F, Viale G, Risio M, Rugge M, Grigioni W, Lonardi S, Zagonel V, Leone F, Noe J, Ciardiello F, Pinto C, Labianca R, Mosconi S, Graiff C, Aprile G, Frau B, Garufi C, Loupakis F, Racca P, Tonini G, Lauricella C, Veronese S, Truini M, Siena S, Marsoni S, Gambacorta M (2015) Assessment of a HER2 scoring system for colorectal cancer: results from a validation study. Mod Pathol 28(11): 1481-1491.

Yaeger R, Cercek A, O’Reilly EM, Reidy DL, Kemeny N, Wolinsky T, Capanu M, Gollub MJ, Rosen N, Berger MF, Lacouture ME, Vakiani E, Saltz LB (2015) Pilot trial of combined BRAF and EGFR inhibition in BRAF-mutant metastatic colorectal cancer patients. Clin Cancer Res 21: 1313-1320.

Zheng Z, Liebers M, Zhelyazkova B, Cao Y, Panditi D, Lynch KD, Chen J, Robinson HE, Shim HS, Chmielecki J, Pao W, Engelman JA, Iafrate AJ, Le LP (2014) Anchored multiplex PCR for targeted next-generation sequencing. Nat Med 20: 1479-1484.

(c) (1) (2) This work is licensed under the Creative Commons (c) national License. To view a copy of this license, visit http:// creativecommons.org/licenses/by-nc-sa/4.0/ 